Ambiente \& Água - An Interdisciplinary Journal of Applied Science
ISSN 1980-993X - doi:10.4136/1980-993X
www.ambi-agua.net
E-mail: ambi.agua@gmail.com

\title{
Identificação de fontes de geração de resíduos sólidos em uma unidade de alimentação e nutrição
}

\author{
doi:10.4136/ambi-agua.1640 \\ Received: 04 May 2015; Accepted: 11 Aug. 2015 \\ Mariana Gardin Alves ${ }^{1 *}$; Mariko Ueno ${ }^{2}$ \\ Universidade de Taubaté (UNITAU), Taubaté, SP, Brasil \\ ${ }^{1}$ Programa de Pós-Graduação em Ciências Ambientais \\ ${ }^{2}$ Instituto Básico de Biociências \\ *Autor correspondente: e-mail: mariana_gardin@yahoo.com.br, \\ maritieue@gmail.com
}

\section{RESUMO}

O serviço de alimentação coletiva é identificado como uma grande fonte de desperdício de alimentos. Para obter dados detalhados de perdas de alimentos e geração de resíduos neste setor, os resíduos de uma unidade de alimentação e nutrição (UAN) foram classificados em categorias: perdas no estoque e armazenamento, perdas no processamento dos alimentos, na distribuição e na devolução. O estudo teve como objetivo identificar e quantificar os resíduos gerados em uma UAN inserida em uma multinacional produtora de peças automobilísticas, localizada no município de Taubaté, SP, durante cinco dias e propor ações pertinentes à redução do impacto ambiental baseado no princípio dos três "Erres". Para servir 2.740 refeições foram gerados 486,6 kg de resíduos sólidos, resultando em um per capita médio de $0,177 \mathrm{~kg} /$ comensal/dia de resíduos. A geração de resíduos ficou distribuída em: $58,0 \%$ no processamento de alimentos, $31,9 \%$ na devolução e o $10,1 \%$ no estoque e armazenamento. Do total de resíduos $85 \%$ eram orgânicos e derivados de: remoção de partes indesejáveis de hortaliças e carnes, restos de alimentos, sobras dos comensais, alimentos vencidos e amostras de alimentos e $15 \%$ eram resíduos compostos de papel/papelão, plásticos e latas. A maior geração de resíduos se deu no descarte de partes não comestíveis dos alimentos, sobras de alimentos produzidos e resto-ingestão, resultados esses relacionados ao desperdício dos alimentos, $100 \%$ destinados à compostagem. Quanto aos demais resíduos $80 \%$ eram destinados à reciclagem e $20 \%$ para o aterro sanitário.

Palavras-chave: ciências ambientais, desperdício de alimentos, serviço alimentar.

\section{Identification of sources of solid waste generation in a food and nutrition unit}

\begin{abstract}
Collective food service is considered a major source of food waste. In order to acquire detailed data of food loss and waste generation in this sector, the waste of one Food and Nutrition Unit (FNU) was classified into categories: inventory losses and storage losses in food processing, distribution and return. The study sought to identify and quantify the waste
\end{abstract}


generated over five days at a FNU located inside an automobile parts manufacturing shop in the city of Taubate, SP, and we proposed an action plan to reduce the environmental impact based upon the three r's principle. In order to serve 2,740 meals, $486.6 \mathrm{~kg}$ of solid waste were generated, resulting in an average per capita of $0.177 \mathrm{~kg} /$ day of waste. The waste was distributed as follows: $58.0 \%$ in food processing, $31.9 \%$ in returns and $10.1 \%$ in stock and storage. Of the total solid waste, $85 \%$ was organic compounds of unwanted portions of vegetables and meat, food scraps, leftovers from dinners, expired food and food samples, and $15 \%$ was composed of waste paper/cardboard, plastics and cans. The largest waste generation was due to the disposal of inedible food, food scraps produced and rest-intake, these results are related to waste food, $100 \%$ intended for composting. As for the other waste, $80 \%$ was destined for recycling and $20 \%$ was taken to the landfill.

Keywords: environmental sciences, food service, waste food.

\section{INTRODUÇÃO}

Medidas sustentáveis precisam ser implementadas no setor de serviços de alimentação para reduzir o desperdício de alimentos, melhorar a eficiência e diminuir a geração de resíduos que são dispostos no ambiente.

Uma das maiores e mais preocupantes problemáticas em torno dos resíduos sólidos estão relacionados ao seu destino e todas as consequências advindas deste para a população atual e futuras gerações (Lopes e Fonseca, 2013; Malta et al., 2008). A destinação inadequada leva à degradação ambiental, além de constituir um meio para que haja o desenvolvimento e proliferação de vetores, ameaçando a saúde da população de maneira geral (Rodrigues, 2007).

O gerenciamento de resíduos sólidos historicamente se baseou na coleta e afastamento desses resíduos e ao longo do tempo, quando ocorre de maneira eficiente cria uma sensação mágica em que o problema foi resolvido e leva-se tempo para perceber o problema da falta de gerenciamento de resíduos sólidos e tratamento dos resíduos. O processo, quando prestado com eficiência, cria a sensação mágica na população de que o problema foi resolvido e levam tempo para perceber o problema pela falta de gerenciamento de resíduos sólidos (Philippi Jr., 2005).

De acordo com a Pesquisa Nacional de Saneamento Básico (IBGE, 2010) os resíduos sólidos gerados nos municípios brasileiros no ano de 2008 tiveram com principal destino os vazadouros a céu aberto $(50,8 \%)$, seguidos de aterro sanitário $(27,7 \%)$ e aterros controlados $(22,5 \%)$ (Brasil, 2010).

Com a intenção em compartilhar a responsabilidade do gerenciamento de resíduos sólidos, a lei 12.305 de 2010 prevê que os geradores estão sujeitos à elaboração de plano de gerenciamento de resíduos sólidos: resíduos dos serviços públicos de saneamento básico, resíduos industriais, resíduos de serviços de saúde, resíduos de mineração, além dos estabelecimentos comerciais, que gerem resíduos perigosos ou nãos, porém sua natureza, composição ou volume não são equiparados aos resíduos domiciliares. Foi determinado que os rejeitos tivessem destino ambientalmente adequado, estabelecendo a extinção de vazadouros a céu aberto a partir do mês de agosto de 2014 (Brasil, 2010). Os restaurantes para coletividade devem elaborar o plano de gerenciamento de resíduos e pela natureza dos serviços prestados, os resíduos podem ser classificados como os de estabelecimentos comerciais (Albertoni, 2013).

A alimentação coletiva é representada pelas atividades de alimentação e nutrição realizadas nas UANs (Abreu et al., 2011), que podem estar localizadas no subsetor de um trabalho e englobam diferentes formas de servir refeições aos trabalhadores, podem também 
estar localizadas em hospitais, ambulatórios, asilos, orfanatos, prisões entre outros (Proença et al., 2005).

Segundo dados da Associação Brasileira das Empresas de Refeições Coletivas a dimensão e a importância do setor de alimentação coletiva na economia nacional podem ser medidas a partir dos números gerados pelo segmento no ano 2014 o mercado de refeições coletivas como um todo forneceu 12,2 milhões de refeições/dia, movimentou cerca de 18,3 bilhões de reais por ano, ofereceu 210 mil empregos diretos, consumiu diariamente um volume de 6,5 mil toneladas de alimentos e representou para os governos uma receita de 1,6 bilhões de reais anuais entre impostos e contribuições (ABERC, 2015).

Segundo Carneiro et al. (2010) em uma UAN, a geração de resíduos é em média de $0,2 \mathrm{~kg} /$ comensal/dia. Atualmente há poucas ações relacionadas aos impactos ambientais provocados pela produção de refeições para a coletividade. Os estudos existentes estão relacionados ao desperdício dos alimentos prontos, entretanto, existem outras formas de minimizar, entre eles, a diminuição dos resíduos sólidos em todas as etapas de produção (Corrêa, 2014). Considerando o número de refeições produzidas no setor e a quantidade expressiva de resíduos sólidos gerados, justifica-se estudar a geração de resíduos sólidos em UANs, com a intenção de minimizar os impactos ambientais decorrentes dessa atividade.

A perda de alimentos ao longo de toda a cadeia produtiva representa uma significativa perda de recursos investidos na produção de alimentos, transporte e armazenamento. Desde recursos como, gastos de energia, água e insumos agrícolas são cada vez mais escassos e devem ser aplicados de forma eficiente e de forma sustentável.

O objetivo do presente trabalho consistiu em identificar e quantificar os resíduos sólidos orgânicos e recicláveis gerados na produção e distribuição de refeições em uma UAN e propor ações pertinentes à redução da geração de resíduos sólidos e destino desses para aterros sanitários.

\section{MATERIAL E MÉTODOS}

Tratou-se de um estudo transversal, quantitativo e descritivo, aprovada pelo Comitê de Ética, parecer consubstanciado número 949.465, que ocorreu no município de Taubaté, estado de São Paulo, em novembro de 2014 em uma Unidade de Alimentação e Nutrição (UAN) inserida em uma multinacional de produção de peças automobilísticas, que foi contratada para terceirizar a administração da cozinha e do refeitório, a produção era em torno de 1000 refeições diárias (550 almoços, 275 jantares e 175 ceias).

A UAN ofertava a refeição principal para os três turnos, sendo o mesmo cardápio, composto de: 4 tipos de salada, sopa, arroz, feijão, 3 tipos de guarnição, 3 tipos de prato proteico, opção ovo ou omelete, sobremesa doce e fruta, refresco. Ainda eram disponíveis para os clientes portadores de patologias e deficiências associadas à nutrição outras preparações denominadas como dieta, composta de: arroz integral, prato proteico e guarnição (hortaliça), elaboradas com menor quantidade de lipídio e isenta de sal. As refeições eram distribuídas pelo sistema de cafeteria mista, o colaborador da UAN servia apenas as preparações proteicas e guarnição.

O estudo foi dividido em três etapas:

$1^{\text {a }}$ Etapa

Foi aplicado um questionário ao nutricionista (responsável técnico), contendo perguntas abertas e fechadas com a intenção de obter informações sobre a jornada de trabalho, número de refeições servidas e a rotina quanto a seleção, pesagem e destino dos resíduos sólidos gerados na produção e distribuição de refeições. 


\section{$2^{\circ}$ Etapa}

Nessa etapa ocorreu a pesagem dos resíduos sólidos gerados na produção da refeição almoço, durante 5 dias (segunda-feira a sexta-feira) entre $6 \mathrm{~h}$ e $15 \mathrm{~h}$.

Os resíduos sólidos foram divididos em resíduos orgânicos (provenientes de alimentos), resíduos não recicláveis (papel toalha e guardanapos engordurados) e resíduos recicláveis (papel/papelão, plástico, lata, vidro).

Foram consideradas três áreas de geração de resíduos:

a) área de estoque - foram considerados os resíduos orgânicos e resíduos recicláveis oriundos das atividades relacionadas ao recebimento de mercadorias, armazenamento de alimentos e guarda de amostras.

b) área de processamento das refeições - foram considerados:

i. resíduos orgânicos devido à remoção de partes não comestíveis dos alimentos. Para avaliar se houve excesso na remoção foi calculado o fator de correção segundo (Ornellas, 2001). Fator de Correção= peso bruto/ peso líquido;

ii. resíduos orgânicos proveniente de sobras que corresponde aos alimentos distribuídos e não consumidos; segundo (Vaz, 2006). Peso da sobra por cliente $(\mathrm{kg})=$ peso da sobra da produção/ número de refeições servidas;

iii. resíduos recicláveis - foram considerados: papel e papelão, plásticos e latas; papel toalha foi considerado como resíduos orgânicos não recicláveis.

c) área de devolução: foram considerados os alimentos deixados nas bandejas dos clientes. Foi calculado o resto ingestão da refeição segundo Vaz (2006). Resto ingestão per capita $(\mathrm{kg})=$ peso do resto/ número de refeições distribuídas. Guardanapos foram considerados com resíduos orgânicos não recicláveis. Copos e latas e garrafas plásticas forma tidas como resíduos recicláveis.

\section{$3^{\text {a }}$ Etapa}

Abrangeu uma proposta, baseada na literatura, para redução de resíduos sólidos gerados e destinados a aterros sanitários, usando o princípio dos 3 "erres" (reduzir, reutilizar e reciclar), com base em Carneiro et al. (2010).

\section{RESULTADOS E DISCUSSÃO}

A geração de resíduos sólidos na UAN estudada durante 5 dias está apresentada na Tabela 1.

Tabela 1. Total de refeições servidas e total de resíduos sólidos, gerados durante 5 dias, referente ao almoço, em uma UAN, no mês de novembro de 2014 em Taubaté, SP.

\begin{tabular}{lcc}
\hline Dia da semana & N. ${ }^{\circ}$ refeições & $\begin{array}{c}\text { Resíduo sólido } \\
(\mathrm{kg})\end{array}$ \\
\hline Segunda-feira & 561 & 99,9 \\
Terça-feira & 547 & 94,0 \\
Quarta-feira & 556 & 113,7 \\
Quinta-feira & 543 & 94,8 \\
Sexta-feira & 533 & 84,2 \\
\hline Total & $\mathbf{2 . 7 4 0}$ & $\mathbf{4 8 6 , 6}$ \\
\hline
\end{tabular}


O montante de resíduos sólidos gerados na UAN do presente estudo foi menor do que os apresentados em outros estudos, o per capita foi de $0,177 \mathrm{~kg} / \mathrm{comensal} / \mathrm{dia}$, sendo a maior parte proveniente do pré-preparo dos alimentos, semelhante ao resultado de Carneiro et al. (2010) que identificaram um per capita médio de 0,200 kg/comensal/dia de resíduos sólidos, sendo a maioria proveniente do pré-preparo e preparo de alimentos. Spinelli e Cale (2009) encontraram um per capita médio de $0,450 \mathrm{~kg} /$ comensal/dia, sendo que desses 0,199 $\mathrm{kg}$ eram oriundos do descarte sobras e resto-ingestão, e no estudo de Lafuente Jr. (2012) em um restaurante comercial encontrou um per capita médio de 0,652 kg/comensal/dia de resíduos sólidos, sendo também a maioria proveniente de sobras e resto-ingestão $(0,345 \mathrm{~kg})$, demonstrando grande desperdício de alimentos prontos para o consumo naquela unidade.

A área do estoque apresentou menor geração de resíduos sólidos, 10,1\% (Tabela 2), contendo entre eles: papel/papelão 3,7\% (Tabela 3) e plástico 0,5\% (Tabela 3) advindo principalmente de embalagens secundárias de alimentos, além do descarte de alimentos que estavam armazenados no estoque ou que foram recebidos de maneira inadequada 3,3\% (Tabela 3) e amostras de alimentos 2,6\% (Tabela 3).

Tabela 2. Proporção de resíduos sólidos gerados, divididos por área, gerado durante 5 dias, referente ao almoço, em uma UAN, no mês de novembro de 2014 em Taubaté, SP.

\begin{tabular}{lc}
\hline Área & $\%$ \\
\hline Estoque & 10,1 \\
Processamento de refeições & 58,0 \\
Devolução & 31,9 \\
\hline Total & $\mathbf{1 0 0 , 0}$ \\
\hline
\end{tabular}

Já a área de processamento de alimentos foi a que apresentou a maior geração de resíduos $58,0 \%$ (Tabela 2), no pré-preparo de hortaliças e frutas foi responsável por $28,5 \%$ dos resíduos sólidos e as carnes $1,8 \%$ (Tabela 3) gerado pela retirada de cascas e partes não comestíveis de frutas, hortaliças e remoção de aparas de carnes, representaram a maior geração de resíduos sólidos do estudo. A sobra de alimentos prontos (Tabela 3) que não foram consumidos representou $20,9 \%$ dos resíduos sólidos.

Nessa área também houve a geração de resíduos recicláveis, os plásticos 3,4\% (Tabela 3) foram resultantes da retirada dos alimentos de suas embalagens primárias e assim como a lata 0,7\% (Tabela), ainda houve a geração de papel/papelão 0,5\% (Tabela 3), resíduos orgânicos não recicláveis $2,1 \%$ (Tabela 3 ) oriundo do descarte de papel toalha utilizado para secagem das mãos dos colaboradores.

A devolução contou com 31,9\% do total de resíduos sólidos, dentre os resultados, o mais expressivo foi o resto ingestão $(27,8 \%)$, além desses, houve resíduos gerados pelo consumo de bebidas, como copos plásticos e garrafas plásticas 3,0\% e latas $0,1 \%$ (Tabela 3), e também de $0,9 \%$ de resíduos orgânicos não recicláveis do descarte de guardanapos engordurados.

Os resíduos sólidos foram gerados principalmente na área de pré-preparo de frutas e hortaliças, resto ingestão e sobras de alimentos (Tabela 3) essas observações levam a crer que há desperdícios. De acordo com Abreu et al. (2011) o desperdício de alimentos, quando existentes, pode ser atribuído a três fatores: fator de correção; sobras (excedentes de alimentos produzidos e não distribuídos) e restos (alimentos distribuídos e não consumidos). 
No pré-preparo de alimentos retiram-se as partes não comestíveis dos alimentos, deixando-os em condições de ser consumidos crus (saladas, frutas) ou de passar para o processo de cocção (carnes e hortaliças cozidas), nesse processo o cálculo do fator de correção pode indicar distorções (Vaz, 2006).

Tabela 3. Total de resíduos sólidos divididos por local e tipo, gerado durante 5 dias, referente ao almoço em uma UAN, no mês de novembro de 2014, em Taubaté, SP.

\begin{tabular}{|c|c|c|}
\hline Local e resíduos sólidos gerados & Peso (kg) & $(\%)$ \\
\hline \multicolumn{3}{|l|}{ Estoque } \\
\hline Papel/papelão & 18,2 & 3,7 \\
\hline Plástico & 2,5 & 0,5 \\
\hline Descarte de gêneros alimentícios & 16,0 & 3,3 \\
\hline Guarda de amostras & 12,6 & 2,6 \\
\hline \multicolumn{3}{|l|}{ Processamento das refeições } \\
\hline Papel/papelão & 2,5 & 0,5 \\
\hline Plástico & 16,6 & 3,4 \\
\hline Lata & 3,5 & 0,7 \\
\hline Resíduos orgânicos não recicláveis (papel toalha) & 10,0 & 2,1 \\
\hline Pré-preparo hortaliças e frutas & 138,9 & 28,5 \\
\hline Pré-preparo carnes & 9,0 & 1,8 \\
\hline Sobras de alimentos no balcão de distribuição & 101,8 & 20,9 \\
\hline \multicolumn{3}{|l|}{ Devolução } \\
\hline Copos descartáveis/garrafas plásticas & 14,5 & 3,0 \\
\hline Resíduos orgânicos não recicláveis (guardanapo) & 4,4 & 0,9 \\
\hline Latas & 0,6 & 0,1 \\
\hline Resto ingestão & 135,5 & 27,8 \\
\hline Total & 486,6 & 100,0 \\
\hline
\end{tabular}

Os resultados de fator de correção encontrados no presente estudo comparados com fator de correção de Silva e Martinez (2008) e Ornellas (2001), apresentaram valores superiores para os alimentos: abobrinha, alface crespa, almeirão, cenoura e rúcula (Tabela 4). Destaque-se que a maioria dos alimentos que ultrapassaram o valor de referência foi as hortaliças folhosas.

Apesar do recebimento de hortaliças folhosas ocorrer diariamente, frequentemente, eram utilizadas no dia seguinte, e nesse espaço de tempo as folhas perdiam qualidade, e por consequência aumentava o valor do fator de correção desses alimentos.

$\mathrm{Na}$ manipulação da rúcula, que antes de ser manipulada pesava $8,0 \mathrm{~kg}$ após a manipulação, resultou em $2,0 \mathrm{~kg}$ de alimento limpo, ocasionando uma perda de 74,9\%. Caso a hortaliça estivesse sido manipulada no mesmo dia que ocorreu a entrega o resultado poderia ser menor, resultando em um menor desperdício e em menor quantidade de resíduos gerados.

A minimização do desperdício de alimentos dentro de um restaurante é resultado de muitos fatores, um deles o correto planejamento de compras, a adaptação da lista de compra com referência no fator de correção dos alimentos demostra eficiência na quantidade adquirida, em todos os produtos alimentícios, refletindo diminuição no custo principalmente 
das carnes e diminuição da geração de resíduos orgânicos principalmente em vegetais (Nogueira et al., 2014).

Tabela 4. Fator de correção encontrado após a manipulação de hortifrutícolas, referente ao almoço, em uma UAN no mês de novembro de 2014, em Taubaté, SP.

\begin{tabular}{lcccc}
\hline Produto & UAN & $\begin{array}{c}\text { Médio da } \\
\text { UAN }\end{array}$ & $\begin{array}{c}\text { Silva e Martinez, } \\
(2008)\end{array}$ & $\begin{array}{c}\text { Ornellas } \\
(2001)\end{array}$ \\
\hline Abobrinha & 1,35 & 1,40 & 1,26 & $1,33-1,38$ \\
& 1,44 & & & \\
& 1,59 & & & \\
& 1,53 & & 1,46 & $1,09-1,33$ \\
Alface & 1,47 & & & \\
crespa & 1,43 & \multirow{2}{*}{1,53} & & \\
& 1,61 & & & \\
& 2,00 & & 1,12 & \\
\hline Almeirão & 1,33 & & 1,16 & \\
\hline Cenoura & 1,32 & \multirow{2}{*}{1,70} & 1,57 & \\
\hline Rúcula & 3,08 & & & \\
\hline
\end{tabular}

A alface foi a hortaliça servida com maior frequência durante a semana, o fator de correção (Tabela 4) apresentou valor médio superior ao encontrado por Silva e Martinez (2008) e Ornellas (2001), sugerindo má qualidade do alimento in natura. Além do problema observado quanto ao frescor do alimento utilizado também foi observado falhas na manipulação como descarte de folhas inteiras e integras, e parcialmente integras sendo descartadas com impróprias, caracterizando como falha na manipulação decorrente de falta de treinamento do colaborador.

O segundo resultado que mais gerou resíduo foi o resto ingestão. No total foram desprezados $135,6 \mathrm{~kg}$, correspondendo a $27,8 \%$ do total produzido (Tabela 3 ).

Os valores per capita que variaram de $0,033 \mathrm{~kg}$ a $0,065 \mathrm{~kg}$ (Tabela 5), sendo o per capita médio de $0,049 \mathrm{~kg} /$ comensal/dia (Tabela 5), porém os dois dias que apresentaram maiores resultados (terça-feira e quarta-feira) houve descarte de cascas mamão na terça-feira e cascas de melancia na quarta, o que interfere em uma comparação direta com os valores de referência na literatura.

Para Abreu et al. (2011), o resto ingestão deve ser avaliado não somente do ponto de vista econômico, como também a falta de integração com o cliente. Partindo do principio que os alimentos são bem preparados o resto deverá ser próximo ao zero. Em que restaurantes com refeições pagas pelo peso não há restos, indicando que o cliente sabe a quantidade de alimento que consegue comer. Vaz (2006) admite ser normal por ser usual em empresas percentuais de restos entre 2 a $5 \%$ da quantidade servida ou de $0,015 \mathrm{~kg}$ a $0,045 \mathrm{~g}$ por pessoa. Outra referência é dada pelo Conselho Federal de Nutricionista, onde expressa percentual aceitável com taxas inferiores a 10\% de resto ingestão (CFN, 2006). 
Augustini et al. (2008) encontraram valores próximos de resto ingestão, per capita entre 0,040 a $0,090 \mathrm{~kg} / \mathrm{comensal} / \mathrm{dia}$, justificando que o alto desperdício se deve à falta de conscientização do cliente em não se comprometer com a redução de desperdício. Gomes e Jorge (2012) ao avaliarem resto ingestão de um restaurante comercial encontraram um per capita de $0,020 \mathrm{~kg}$, acreditando que essa quantidade pode estar atrelada que o desperdício pelo alimento deixado no prato resulta em uma sensação de pagar pelo alimento e sentir o reflexo do prejuízo no próprio bolso.

Para diminuir esses valores, é importante que o cliente seja conscientizado por campanhas, para que ele sinta que faz parte do processo de redução de desperdício e por consequência a geração de resíduos. Além de campanhas deve se dar a atenção na elaboração do cardápio e com a inclusão de alimentos com características organolépticas desejáveis e preparações típicas da região, já que esses fatores têm grande influência no resto ingestão (Pereira, 2009).

Como os resultados encontrados de resto ingestão mostram se acima do esperado por Vaz (2006) e não foi possível obter os dados referentes, como a quantidade de alimentos porcionados pelo colaborador da UAN, avaliação das características organolépticas do cardápio e assim como a aceitação das preparações, esses fatores devem ser avaliados pelo nutricionista responsável pela UAN com a intenção de reduzir esses resultados.

Tabela 5. Resultados de resto ingestão, gerados durante 5 dias na devolução, referente a almoço em uma UAN, no mês de novembro de 2014, em Taubaté, SP.

\begin{tabular}{lccc}
\hline $\begin{array}{l}\text { Dia da } \\
\text { semana }\end{array}$ & $\begin{array}{c}\text { Número de } \\
\text { refeições servidas }\end{array}$ & $\begin{array}{c}\text { Resíduo } \\
\text { total }(\mathrm{kg})\end{array}$ & $\begin{array}{c}\text { Resíduo } \\
\text { per capita }(\mathrm{kg})\end{array}$ \\
\hline Segunda & 561 & 27,0 & 0,048 \\
Terça & 547 & 36,0 & 0,065 \\
Quarta & 556 & 32,5 & 0,058 \\
Quinta & 543 & 22,0 & 0,040 \\
Sexta & 533 & 18,0 & 0,033 \\
\hline Total & $\mathbf{2 7 4 0}$ & $\mathbf{1 3 5 , 5}$ & \\
\hline Média & $\mathbf{5 4 8}$ & & $\mathbf{0 , 0 4 9}$ \\
\hline
\end{tabular}

O terceiro maior resultado em geração de resíduos encontrado foram as sobras de alimentos, aqueles que restaram no balcão térmico após o término do período da distribuição de refeições.

Para Abreu et al. (2011) não existe um porcentagem ideal de sobras, cada restaurante deve medir as sobras ao longo do tempo e estabelecer um parâmetro próprio da unidade. Porém, para Vaz (2006) a busca por percentuais menores de sobra deve ser constante, mas admitem-se como aceitáveis percentuais de até $3 \%$ ou de $0,007 \mathrm{~kg}$ a $0,025 \mathrm{~kg}$ por pessoa.

$\mathrm{Na}$ UAN estudada não tem como rotina o controle de sobras, no período estudado, houve geração de 101,8 kg (Tabela 6) de resíduos sólidos, gerando um per capita médio de $0,037 \mathrm{~kg} /$ comensal/dia (Tabela 6), valores superiores ao proposto por Vaz (2006).

Considerando os 5 dias pesquisados as preparações que mais apresentaram desperdício foram: sopa, arroz, feijão, escondidinho de carne seca, repolho cozido, peixe assado a portuguesa, seleta de legumes, arroz brasileiro e purê de batata. O mês estudado apresentou 
médias elevadas na temperatura o que pode explicar a diminuição na aceitação de pratos quentes, como a sopa.

Abreu et al. (2011) sugerem que ao encontrar valores elevados de sobras deve analisar se algum dos pratos não estava de acordo com o hábito do cliente, se houve algum motivo para redução de clientes nesse dia ou ainda se houve algum erro de cálculo de quantidade de alimentos. Para Augustini et al. (2008) o excesso de sobras pode estar associado a erros no planejamento de cardápio como repetição de determinadas preparações, ou falhas na produção, como má aparência nas preparações não tornando os pratos atrativos.

Para diminuir as sobras são necessárias ações como: planejamento correto do número de refeições, avaliação do rendimento da matéria-prima, envolvimento da equipe para traçar metas atingíveis de controle de sobra, treinamento e conscientização da equipe, além de preparar alimentos aos poucos, sempre que possível, manter durante todo o tempo de distribuição uma excelente apresentação dos pratos (Augistini et al., 2008).

Tabela 6. Total de resíduos orgânicos provenientes de sobras no balcão térmico, gerado durante 5 dias, referente ao almoço em uma UAN, no mês de novembro de 2014, em Taubaté, SP.

\begin{tabular}{lccc}
\hline $\begin{array}{l}\text { Dia da } \\
\text { semana }\end{array}$ & $\begin{array}{c}\text { Número de refeições } \\
\text { Servidas }\end{array}$ & $\begin{array}{c}\text { Resíduo total } \\
(\mathrm{kg})\end{array}$ & $\begin{array}{c}\text { Resíduo } \\
\text { per capita }(\mathrm{kg})\end{array}$ \\
\hline Segunda & 561 & 11,6 & 0,020 \\
Terça & 547 & 21,2 & 0,038 \\
Quarta & 556 & 28,5 & 0,051 \\
Quinta & 543 & 17,8 & 0,032 \\
Sexta & 533 & 22,7 & 0,042 \\
\hline Total & $\mathbf{2 7 4 0}$ & $\mathbf{1 0 1 , 8}$ & \\
\hline Média & $\mathbf{5 4 8}$ & & $\mathbf{0 , 0 3 7}$ \\
\hline
\end{tabular}

\subsection{Composição e destinos dos resíduos sólidos gerados}

Do total de resíduos gerados, 85\% eram orgânicos (Figura 1), principalmente compostos de cascas de alimentos e remoção de partes de alimentos são utilizados, restos de alimentos descartados pelos clientes e sobras de alimentos prontos, e $15 \%$ eram resíduos sólidos recicláveis e não recicláveis (Figura 2), sendo constituídos de plásticos (6,9\%), papel/papelão $(4,3 \%)$, papel toalha e guardanapos engordurados $(3,0 \%)$ e lata $(0,8 \%)$.

$\mathrm{O}$ gerenciamento de resíduos gerados na UAN é de responsabilidade da multinacional contratante. Dessa maneira a UAN só possui como responsabilidade a separação dos resíduos sólidos, em orgânicos, recicláveis (papel/papelão, plástico, vidro, lata e óleo) e orgânicos não recicláveis (guardanapo e papel toalha).

Conforme resultados obtidos na aplicação do questionário, a nutricionista informou que após separação dos resíduos, esses são coletados por empresas especializadas, sendo que os resíduos orgânicos têm como destino a compostagem, os resíduos recicláveis são recolhidos por uma empresa que os destina a reciclagem e apenas os resíduos orgânicos não recicláveis são recolhidos e destinados ao aterro sanitário.

A destinação final ambientalmente adequada de resíduos sólidos inclui a reutilização, a reciclagem, a compostagem, a recuperação e o aproveitamento energético (Brasil, 2010).

Considerando que apenas $3 \%$ de todo o total de resíduos gerados são destinados ao aterro sanitário, por não ser possível reciclar, a UAN estudada apresenta-se adequada em suas ações. 


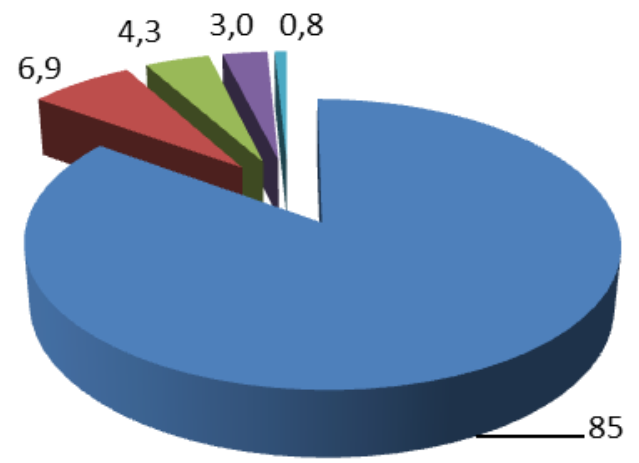

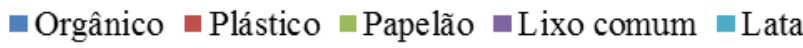

Figura 1. Percentual de resíduos sólidos, gerados durante 5 dias, referente ao almoço, em uma UAN, no mês de novembro de 2014, em Taubaté, SP.

\subsection{Ações possíveis para diminuição da geração de resíduos sólidos pelo princípio dos 3 "erres" (reduzir, reutilizar e reciclar)}

Para produzir refeições para a coletividade, as UANs geram resíduos sólidos, e a quantidade desses resíduos são influenciados por diversos fatores, porém ações são cabíveis para a diminuição. Sendo que essas ações podem ser norteadas pelo Princípio dos Três "Erres" (3R's), que são: reduzir, reutilizar e reciclar, aplicadas a realidades da UAN, conforme referência de Carneiro et al. (2010). Entre ações dos Três "Erres" destacam-se:

\subsubsection{Reduzir}

a) Reduzir a geração de resíduos recicláveis na utilização de embalagens de produtos de limpeza e copo plástico. Entre as ações de reduzir os resíduos inorgânicos gerados em uma UAN, Carneiro et al. (2010) propõe que as empresas devem dar preferência para produtos de higiene que tenham refil e pela utilização de copos de vidro ao invés de copos de plástico. Menezes (2002) com a finalidade de reduzir resíduos recicláveis oriundos de copos plásticos não conseguiu implantar a utilização de copos de vidro, mas conseguiu uma redução de 50\% do descarte pela conscientização dos usuários em evitar o consumo excessivo de copos após um trabalho educativo desenvolvido na UAN.

b) Reduzir a geração de resíduos orgânicos no estoque pelo controle de mercadoria no estoque. Os alimentos podem chegar do fornecedor em excelentes condições, mas mesmo assim, ocorrer perda da qualidade dos alimentos no armazenamento, por serem armazenados em locais inadequados, seja por não existirem equipamentos de refrigeração suficientes, por falta de espaço e ainda por falta de cuidados ou conhecimento para armazenar os produtos não controlando a validade de maneira correta (Vaz, 2006).

c) Reduzir a geração de resíduos sólidos pela utilização da ficha técnica. A ficha técnica é um instrumento útil para auxiliar o planejamento de cardápio, informando dados da preparação como: per capita, fator de correção, fator de cocção, rendimento e número de porções, auxiliando a execução e na identificação da quantidade de alimentos a serem produzidos, além de permitir o controle financeiro (Akutsu et al., 2005). O cálculo das quantidades a serem adquiridas deve-se basear nas quotas diárias per capita, levando em conta o fator de correção que prevê as perdas inevitáveis. Portanto sabe-se a quantidade por pessoa e a quantidade diária de cada alimento segundo o cardápio para aquele dia, ficando fácil planejar (Ribeiro, 2002). 
d) Reduzir pela avaliação constantemente do fator de correção dos alimentos. Amaral (2008), identificou que um dos problemas relacionados a produção de refeições de uma UAN hospitalar estava relacionado a diminuição do rendimento no preparo de hortifrutícolas, resultando na falta do alimento no balcão distribuição, motivo que não estava relacionado a quantidade de matéria-prima disponível ou pela quantidade de alimento previsto para o número de refeições servidas. Associou a falta do alimento por falhas no pré-preparo, resultado pela manipulação excessiva ou pela falta de qualidade da mercadoria. Chegando a conclusão que as atividades no pré-preparo devem ser padronizadas quanto a forma de execução, além da implantação de um formulário especifico para coletas de dados e identificação o fator de correção, possibilitando a criação de sua própria tabela de fator de correção permitindo uma avaliação constante para identificar as falhas no preparo de vegetais e frutas.

e) Reduzir pela implantação a compra de alimentos minimamente processados. $\mathrm{O}$ proposito da compra é deter de um alimento pronto para usar que não necessite de nenhuma preparação posterior a sua utilização, em termos de seleção, limpeza, lavagem ou cortes, além da grande vantagem na eliminação do desperdício e na geração de resíduos (Junqueira; Luengo, 2000). No estudo realizado por Degiovanni et al. (2010) ao compararem o valor entre a compra de alimentos minimamente processados com alimentos in natura em uma UAN, observaram que dependendo da sazonalidade, a compra de alguns alimentos já pré-preparados como abobrinha, cenoura, chuchu e mandioquinha saíram com preço inferior ao in natura. A compra de alimentos minimamente processados deve ser avaliada pelo gestor da UAN, além da possibilidade na diminuição gastos, representaria uma diminuição na geração de resíduos sólidos na UAN.

f) Reduzir o desperdício de alimentos devolvidos no prato dos clientes. Na pesquisa realizada por Silva et al. (2010) a fim de diminuir os restos de alimentos advindos de pratos dos clientes promoveu campanhas sobre a conscientização sobre o desperdício de alimentos, no qual conseguiu uma redução imediata de $43,24 \%$ dos resíduos, porém com o passar dos dias foi realizado outra medição no qual representou uma mudança de comportamento dos clientes, porém com uma redução menor, de 27,20\%. Dessa maneira as campanhas devem acontecer de maneira periódica na empresa para surtirem melhor efeito.

g) Reduzir pela minimização da frequência de preparações menor índice de aceitação com a intenção de reduzir restos deixados nos pratos; Soares et al. (2011) ao avaliarem o desperdícios de alimentos de uma UAN, observaram que entre o grupos de alimentos as saladas foram as preparações que mais contribuíram com o desperdício, evidenciou-se que as saladas disponíveis no cardápio se mantiveram no mesmo padrão de corte e não foram acrescidas de outros ingredientes para sua diferenciação, causando monotonia e baixa aceitação.

h) Reduzir equívocos pela identificação dos nomes das preparações servidas para evitar restos. Villan e Alves (2010) fizeram uma pesquisa em uma UAN com o objetivo de verificar a quantidade de alimentos desperdiçados e possíveis causas, e identificaram que $8 \%$ dos entrevistados já desperdiçaram alimentos por cometer engano por se servirem de um alimento pensando que era outro, por falta de identificação da preparação servida.

\subsubsection{Reutilizar}

A reutilização de alimentos e/ou aproveitamento integral são técnicas que também podem ser desenvolvidas em UANs. Ribeiro et al. (2014) desenvolveram um trabalho para verificar a aceitação de alimentos que foram utilizados de maneira integral ou pelo aproveitamento de 
cascas para elaboração de outros alimentos, e receitas como: salpicão verde, farofa de casca de melancia, bolo de casca de abacaxi, passaram pelo teste de aceitabilidade com alto percentual de aceitação dos clientes de uma UAN hospitalar, recomendando a sua utilização em outros locais.

Em relação a reutilização de embalagens, de acordo com a legislação sanitária do Estado de São Paulo fica proibido reaproveitar vasilhames de produtos alimentícios para envasar produtos de limpeza (São Paulo, 2013).

\subsubsection{Reciclar}

Para o destino adequado de resíduos recicláveis, a coleta seletiva é uma técnica ecologicamente correta, consiste em separar os resíduos de acordo com a sua natureza e conduzi-los a uma usina de reciclagem para transformação em matéria-prima novamente e assim destina-los a indústria para utilização de novos produtos (Costa et al., 2004).

\section{CONCLUSÃO}

A UAN apresentou uma quantidade de resíduos sólidos per capita inferior aos valores reportados na literatura, mas foi observado que os 3 locais que mais geraram resíduos, coincidem com os que a literatura descreve como os que mais geram desperdício de alimentos em uma UAN associados a resíduos orgânicos.

Apesar dos resultados finais de geração de resíduos serem inferiores aos comparados à literatura, ações baseadas nos 3 "erres" (reduzir, reciclar e reutilizar) são possíveis de serem executadas com a finalidade em diminuir a geração de resíduos sólidos.

O destino final dos resíduos sólidos apresenta-se adequado, sendo que aqueles possíveis de serem recicláveis são destinados à reciclagem e os orgânicos à compostagem, sendo apenas $3 \%$ dos resíduos destinados ao aterro sanitário.

\section{AGRADECIMENTO}

Os agradecimentos ficam destinados ao responsável pela UAN, a nutricionista responsável técnica e por todos os colaboradores da cozinha, que foram receptivos e prestativos para que a coleta de dados ocorresse da melhor forma possível.

\section{REFERÊNCIAS}

\section{ASSOCIAÇÃO BRASILEIRA DAS EMPRESAS DE REFEIÇÕES PARA} COLETIVIDADE - ABERC. História e mercado. 2015. Disponível em: <http://www.aberc.com.br/conteudo.asp?IDMenu=18>. Acesso em: 06 mar. 2015.

ABREU, E. S. et al. Gestão de unidades de alimentação e nutrição: um modo de fazer. 4. ed. São Paulo: Metha, 2011. 352p.

AKUTSU, R. C. et al. A ficha técnica de preparação como instrumento da qualidade na produção de refeição. Revista de Nutrição, v. 18, n. 2, p. 277-279, mar./abr. 2005. http://dx.doi.org/10.1590/S1415-52732005000200012

ALBERTONI, T. A. Caracterização física dos resíduos sólidos gerados em restaurante universitário. 2013. 78f. Trabalho de Conclusão de Curso (Graduaçãoem Engenharia Ambiental) - Universidade Tecnológica Federal do Paraná, Londrina, 2013. 
AMARAL, L. B. Redução do desperdício de alimentos na produção de refeições hospitalares. 2008. 48f. Trabalho de Conclusão de Curso (Gestão Pública) - Faculdade IBGEN, Porto Alegre, 2008.

AUGUSTINI, V. C. M.; KISHIMOTO P.; TESCARO T. C.; ALMEIDA, F. Q. A. Avaliação do índice de resto-ingesta e sobras em unidade de alimentação e nutrição (UAN) de uma empresa metalúrgica na cidade de Piracicaba/SP. Revista Simbio-Logias, v. 1, n. 1, p. 99-110, 2008.

BRASIL. Lei $\mathrm{n}^{\circ}$ 12.305, de 02 de agosto de 2010. Institui a Política Nacional de Resíduos Sólidos; altera a Lei no 9.605, de 12 de fevereiro de 1998; e dá outras providências. Diário Oficial [da] União, Brasília, Seção 1, 03 ago. 2010.

CARNEIRO, C. M. L. et al. Diagnóstico dos resíduos sólidos produzidos no restaurante universitário da UFRN. In: ENCONTRO NACIONAL DE ENGENHARIA DE PRODUÇÃO, 30., out. 2010, São Carlos. Trabalhos... Rio de Janeiro: AGEPRO, 2010.

CONSELHO FEDERAL DE NUTRICIONISTAS - CFN. Resolução CFN no 380 de 09 de dezembro de 2005. Diário Oficial [da] União, Brasília, 10 de jan., 2006.

CORRÊA, M. S. Desafio da gestão de resíduos sólidos em unidades de alimentação e nutrição: proposições para legislação, instituições e formação profissional. 2014. $146 \mathrm{f}$. Tese (Doutorado em Saneamento, Meio Ambiente e Recursos Hídricos) - Universidade Federal de Minas Gerais, Belo Horizonte, 2014.

COSTA, F. X. et al. Estudo qualitativo e quantitativo dos resíduos sólidos do Campus I da Universidade Estadual da Paraíba. Revista de Biologia e Ciência na Terra, v. 4, n. 2, p. 1-10, 2004.

DEGIOVANNI, G. C. et al. Hortaliças in natura ou minimamente processadas em unidades de alimentação e nutrição: quais aspectos devem ser considerados na sua aquisição. Revista de Nutrição, v. 23, n. 5, p. 813-822, set./out. 2010. http://dx.doi.org/10.1590/S1415-52732010000500011

GOMES, G. S.; JORGE, M. N. Avaliação do índice de resto-ingestão e sobras em uma unidade produtora de refeição comercial em Ipatinga-Mg. Revista Nutrir Gerais, v. 6, n. 10, p. 857-868, fev./jul. 2012.

INSTITUTO BRASILEIRO DE GEOGRAFIA E ESTATÍSTICA - IBGE. Pesquisa nacional de saneamento básico 2008. Rio de Janeiro, 2010. 219p.

JUNQUEIRA, A. H.; LUENGO, R. F. A. Mercados diferenciados de hortaliças. Horticultura Brasileira, v. 18, n. 2, p. 95-99, 2000. http://dx.doi.org/10.1590/S010205362000000200003

LAFUENTE Jr., A. N. A. Resíduos sólidos em restaurante comercial: um estudo de caso na cidade de Santos/SP. Revista de Tecnologia Aplicada, v. 6, n. 2, p. 44-61, maio/ago. 2012 .

LOPES, M. L.; FONSECA, V. V. Estudo do manejo dos resíduos de um restaurante institucional da região Sul Fluminense. Interbio, v. 7, n. 1, p. 47-53, 2013.

MALTA, M. B.; NANZER, C. M.; ALMEIDA, F. Q. A. Implantação do processo de reciclagem de lixo em uma unidade de alimentação e nutrição (UAN). Revista SimbioLogias, v. 1, n. 2, p. 1-9, nov. 2008. 
MENEZES, R. L. et al. Projeto de minimização de resíduos sólidos no restaurante central do campus de São Carlos da Universidade de São Paulo. In: ENCONTRO DE ENGENHARIA DE PRODUÇÃO, 32., 23 a 25 de outubro de 2002, Curitiba. Trabalhos... Rio de Janeiro: AGEPRO, 2002.

NOGUEIRA, A. R.; FORTES NETO, P.; UENO, M. Gestão em um restaurante para redução de custos e de resíduos sólidos. Curitiba: CRV, 2014. v.1. 72p.

ORNELLAS, L. H. Técnica dietética: seleção e preparo de alimentos. 6. ed. São Paulo: Atheneu, 2001. 330p.

PEREIRA, A. S. Avaliação do índice do resto-ingesta e sobras em unidade de alimentação e nutrição de uma empresa na cidade de Caruaru-PE. 2009. 25f. Trabalho de Conclusão de Curso (Graduação em Nutrição) - Faculdade do Vale do Ipojuca, Caruaru, 2009.

PHILIPPI Jr., A. Saneamento, saúde e ambiente: fundamentos para um desenvolvimento sustentável. Barueri: Manole, 2005. 842 p.

PROENÇA, R. P. C. et al. Qualidade nutricional e sensorial da produção de refeições. Revista Nutrição em Pauta, p. 4-16, nov./dez. 2005.

RIBEIRO, C. S. G. Análise de perdas em unidades de alimentação e nutrição (UANs) industriais: estudo de caso em restaurantes industriais. 2002. 128f. Dissertação (Mestrado em Engenharia de Produção) - Programa de Pós-Graduação em Engenharia de Produção, Universidade Federal de Santa Catarina, Florianópolis, 2002.

RIBEIRO, T. L. et al. Proposta de utilização de resíduos orgânicos em unidade de alimentação e nutrição hospitalar, Belo Horizonte, MG. Revista Higiene Alimentar, v. 28, n. 238/239, p. 41-45, 2014.

RODRIGUES, G. K. D. Segurança alimentar em UAN escolar: aspectos higiênicosanitários e produção de resíduos orgânicos. Dissertação (Mestrado em Ciência da Nutrição) - Universidade Federal de Viçosa, Viçosa, 2007.

SÃO PAULO (Estado). Centro de Vigilância Sanitária. Portaria n. 5, de 9 de abril de 2013. Diário Oficial Estadual, São Paulo, 19 abr. de 2013.

SILVA, A. M. et al. Avaliação do índice de resto ingesta após campanha de conscientização dos clientes contra o desperdício de alimentos em um serviço de alimentação hospitalar. Revista Simbio-Logias, v. 3, n. 4, p. 43-56, jun. 2010.

SILVA, S. M. S.; MARTINEZ, L. Cardápio: guia prático para a elaboração. 2. ed. São Paulo: Roca, 2008. 281p.

SOARES, I. C. C.; SILVA, E. R.; PIORE, S. E.; RIBEIRO, R. C. L.; PEREIRA, M. M. L. S.; PINEHIRO-SANT'ANA, H. M. Quantificação e análise do custo da sobra limpa em unidades de alimentação e nutrição de uma empresa de grande porte. Revista de Nutrição, v. 24, p. 593-604, jul./ago. 2011. http://dx.doi.org/10.1590/S141552732011000400008

SPINELLI, M. G. N.; CALE, L. R. Avaliação de resíduos em uma unidade de alimentação e nutrição. Revista Simbio-Logias, v. 2, n. 1, p. 21-30, 2009. 
VAZ, C. V. Restaurantes: controlando custos e aumentando lucros. Brasília: Metha, 2006. 196 p.

VILLAN, S. F.; ALVES, F. S. Desperdício de alimentos em uma Unidade de Alimentação e Nutrição. Nutrição Brasil, v. 9, n. 5, p. 276-280, 2010. 